\title{
Hematological profile of wild-captured Indian Flying Fox (Pteropus giganteus) in Bangladesh
}

\author{
Hossain $\mathrm{MB}^{1}$, Islam $\mathrm{MN}^{2}$, Yasin $\mathrm{MG}^{3}$, Hassan $\mathrm{MM}^{1}$, Islam SKMA ${ }^{1}$ and Khan $\mathrm{SA}^{1}$ \\ ${ }^{l}$ Department of Physiology, Biochemistry and Pharmacology, ${ }^{2}$ DVM Intern Student, Chittagong Veterinary and \\ Animal Sciences University, Khulshi, Chittagong-4202, Bangladesh, ${ }^{3}$ PhD Fellow, Department of Parasitology, \\ Bangladesh Agricultural University, Mymensingh
}

[Received: October 22, Accepted: December 26, 2013]

\begin{abstract}
The current study was conducted to examine hematological parameters of large frugivorous bats under the class mammalian. Ninety (90) clinically healthy large frugivorous bats were captured and anesthetized for blood collection from brachial vein. Captured bats were divided into three groups' based on different criteria such as sex, age and body condition score. Red blood cell (RBC) count, hemoglobin (Hb), hematocrits (Hct), mean corpuscular volume (MCV), mean corpuscular hemoglobin ( $\mathrm{MCH}$ ), mean corpuscular hemoglobin concentration(MCHC), red cell distribution width (RDWs), white blood cell (WBC) count, platelets (PLT), mean platelet volume (MPV), platelet distribution width (PDW) were determined by automated hematology analyzer and erythrocyte sedimentation rate (ESR) was determined manually. RBC and MCV values were found significantly $(p<0.05)$ higher in male bats. On the other hand, the RBC count, $\mathrm{HCT}, \mathrm{Hb}, \mathrm{RDW}$ and PLT were significantly $(p<0.05)$ higher in adults than in juveniles bats. Among the health state RBC, HCT and PLT values were significantly $(p<0.05)$ higher in good-health bats. However, some values were varied in different groups, but they were not statistically significant $(p>0.05)$. The values from this study can be used to create reference of hematological profile of bat found in Indian subcontinent, and can make up the first comprehensive hematological study for this highly endangered species.
\end{abstract}

Key words: Bat, hematology, body condition, age, sex

\section{INTRODUCTION}

Bats are the only true flying mammals and have undergone various enigmatic modifications to meet the stress of flight adaptations. The Indian flying fox under the family Pteropodae is the largest fruits bat in Indian subcontinent are commonly found throughout the Indian subcontinent. The species is widespread in all over the country besides human settlement. They play important role in maintaining ecological balance. They are living in close association with humans and feeding on cultivated and wild fruits. They have economic or medical value to humans as well. They are of agricultural importance because of their diverse feeding habits. This is evident from the fact that the fruit bats feeding on different seasonal fruits, date juice and farmers use their guano as fertilizer. Bats feeding on nectar are responsible for fertilization or crossfertilization of flowers and farmers uses their guano as fertilizer. They play crucial role in pollinating, seed dispersal and natural forest regeneration in tropics. Bats may be harmful to humans if they are infected with rabies or any other virus or bacteria that may be transmitted by accidental cases of bat bites. Besides this contributions and diversities, bats have adapted themselves to different ecological niche as well $[1,2,3]$. These adaptations suggest various physiological adjustment including blood composition and chemistry. From the perusal of literature it appears that the blood physiology of bats is as diverse feeding habits e.g. insectivores, vampires, piscivores, frugivores ${ }^{[4]}$.

The normal hematological values of bats from South Asia are scarce ${ }^{[5]}$ and estimation of blood profiles is non- existent in this native condition. In south Asian perspective, McLaughlin et al., ${ }^{[6]}$ has conducted a limited hematological and serum chemistry study in Haryana, India and hematological parameter of three Microchiropteran species has been conducted by Rotanossoria et al., ${ }^{[5]}$ in Sri Lanka.

Plasma biochemistry and hematological analyses of wild-caught animals may be used to assess population health and can serve as indicators of poor nutritional status, diseases, trauma, and environmental changes, such as altered habitat quality. These values have been used to guide management of captive and wild populations. However, for correct interpretation, reference ranges need to be established. Full hematology and serum chemistry panels of wild bats are necessary to complete base-line data; however, the data and analyses presented here may be used as a reference for future health assessments of captive or wild Indian flying foxes. Thus providing a more comprehensive hematological reference for members of one of the most ecologically and evolutionarily successful groups of mammals. Therefore, this study has been conducted to assess the health condition of Indian flying fox by determining the hematological value. 


\section{MATERIALS AND METHODS}

Study area:Ninety (90) apparently healthy Pteropus giganteus were captured using mist-net at Cox's Bazar district in Bangladesh from a colony of approximately 1000 bats. This colony is situated besides human settlement area and continued throughout the year.

Table-1: Hematological values of male and female wild-caught large frugivorous (Pteropus giganteus) bats

\section{Sample collection:}

The Pteropus giganteus $(\mathrm{n}=90)$ were captured over a period of seven nights in late October, 2012, with the use of an 18-m mist-net suspended between two 12$\mathrm{m}$ bamboo masts. Captured bats were placed in pillow (cloth bags) until processing. Body weights were measured by balance. Sex, age and body condition score were recorded for each bat.

\section{Category}

Parameter

Male

Female

Pvalue

$\mathrm{n} \quad \mathrm{Mean} \pm \mathrm{SE} \quad 95 \% \mathrm{CI} \quad \mathrm{n} \quad$ Mean $\pm \mathrm{SE} \quad 95 \% \mathrm{CI}$

M M

\begin{tabular}{|c|c|c|c|c|c|c|c|}
\hline RBC $\left(10^{6} / \mu \mathrm{L}\right)$ & 51 & $10.3 \pm 0.3$ & $9.7-10.8$ & 38 & $9.8 \pm 0.4$ & $9.1-10.6$ & 0.370 \\
\hline $\mathrm{Hb} \mathrm{g} / \mathrm{dL}$ & 51 & $14.9 \pm 0.3$ & $14.3-15.5$ & 37 & $14.3 \pm 0.9$ & $12.5-16.2$ & 0.561 \\
\hline НCТ \% & 51 & $52.2 \pm 1.5$ & $49.2-55.2$ & 38 & $47.9 \pm 2.0$ & $43.9-51.9$ & 0.086 \\
\hline $\mathrm{MCV} \mathrm{fL}$ & 51 & $50.9 \pm 0.5$ & $50.0-51.8$ & 38 & $49.4 \pm 0.5$ & $48.5-50.4$ & $0.031^{*}$ \\
\hline $\mathrm{MCH} p g$ & 51 & $15.0 \pm 0.2$ & $14.6-15.5$ & 38 & $14.6 \pm 0.3$ & $14.0-15.1$ & 0.339 \\
\hline $\mathrm{ESR} \mathrm{mm}$ in $1^{\mathrm{st}} \mathrm{h}$ & 51 & $0.7 \pm 0.1$ & $0.6-0.9$ & 38 & $0.7 \pm 0.1$ & $0.5-0.8$ & 0.293 \\
\hline WBC $\left(10^{3} / \mu \mathrm{L}\right)$ & 51 & $6.4 \pm 0.7$ & $5.0-7.7$ & 38 & $7.1 \pm 0.8$ & $5.4-8.7$ & 0.506 \\
\hline $\mathrm{MCHC} \mathrm{g} / \mathrm{dL}$ & 51 & $29.4 \pm 0.4$ & $28.6-30.2$ & 38 & $29.5 \pm 0.6$ & $28.2-30.7$ & 0.912 \\
\hline RDWs fL & 51 & $35.2 \pm 0.3$ & $34.6-35.9$ & 38 & $34.4 \pm 0.4$ & $33.7-35.2$ & 0.100 \\
\hline \multirow[t]{2}{*}{$\operatorname{PLT}\left(10^{3} / \mu \mathrm{L}\right)$} & 17 & 775.4 & 661.9- & 14 & 717.4 & $542.2-$ & 0.557 \\
\hline & & 53.6 & 888.9 & & 81.1 & 892.6 & \\
\hline MPV fL & 17 & $8.6 \pm 0.3$ & $8.0-9.3$ & 14 & $8.3 \pm 0.3$ & 7.6-9.0 & 0.438 \\
\hline PDWs fL & 17 & $11.8 \pm 0.9$ & $9.7-13.6$ & 14 & $11.7 \pm 0.9$ & $9.7-13.6$ & 0.939 \\
\hline
\end{tabular}


Table-2: Hematological values of juvenile and adult wild-caught large frugivorous (Pteropus giganteus) bats
Locally available nail polish was used to mark the bat for avoiding recapture. Bats were monitored until recovery and released near their roosting site within 2-2.5 hours after feeding of mango juice.

\section{Category}

Parameter

\begin{tabular}{|c|c|c|c|c|c|c|c|}
\hline \multirow[t]{2}{*}{ Parameter } & \multicolumn{3}{|c|}{ Juvenile } & \multicolumn{3}{|c|}{ Adult } & \multirow[t]{2}{*}{$P$ value } \\
\hline & $\mathrm{n}$ & Mean \pm SEM & 95\% CI & $\mathrm{n}$ & Mean \pm SEM & $95 \% \mathrm{CI}$ & \\
\hline $\left.\mathrm{RBC}\left(10^{6} / \mu \mathrm{L}\right)\right)$ & 36 & $9.4 \pm 0.1$ & $9.2-9.7$ & 52 & $10.5 \pm 0.4$ & $9.8-11.3$ & $0.006^{* *}$ \\
\hline $\mathrm{Hb} \mathrm{g} / \mathrm{dL}$ & 35 & $13.6 \pm 0.3$ & $13.1-14.2$ & 52 & $15.4 \pm 0.7$ & $14.1-16.8$ & $0.016^{* *}$ \\
\hline НСТ \% & 36 & $47.0 \pm 0.8$ & $45.3-48.7$ & 52 & $52.7 \pm 1.9$ & $48.8-56.7$ & $0.009^{* *}$ \\
\hline MCV fL & 36 & $49.6 \pm 0.6$ & $48.4-50.7$ & 52 & $50.7 \pm 0.4$ & $49.9-51.6$ & 0.100 \\
\hline $\mathrm{MCH}$ pg & 36 & $15.0 \pm 0.1$ & $14.7-15.3$ & 52 & $14.7 \pm 0.3$ & $14.1-15.3$ & 0.427 \\
\hline $\mathrm{MCHC} g / \mathrm{dL}$ & 36 & $30.2 \pm 0.3$ & $29.6-30.8$ & 52 & $29.0 \pm 0.5$ & $27.9-30.1$ & 0.060 \\
\hline RDWs fL & 36 & $34.2 \pm 0.4$ & $33.4-35.1$ & 52 & $35.4 \pm 0.3$ & $34.8-36.0$ & $0.031^{* *}$ \\
\hline ESR $m m$ in $1^{\text {st }} h$ & 36 & $0.8 \pm 0.1$ & $0.6-1.0$ & 52 & $0.7 \pm 0.1$ & $0.6-0.8$ & 0.213 \\
\hline WBC $\left(10^{3} / \mu \mathrm{L}\right)$ & 36 & $6.5 \pm 0.8$ & $4.8-8.2$ & 52 & $6.8 \pm 0.7$ & $5.5-8.2$ & 0.735 \\
\hline PLT $\left(10^{3} / \mu \mathrm{L}\right)$ & 12 & $566.8 \pm 38.9$ & $475.0-646.5$ & 18 & $881.4 \pm 58.5$ & 757.9-1005 & $0.0001^{* *}$ \\
\hline MPV fL & 12 & $7.7 \pm 0.41$ & $6.8-8.6$ & 18 & $9.0 \pm 0.2$ & $8.6-9.5$ & $0.015^{* *}$ \\
\hline PDWs fL & 12 & $10.3 \pm 1.0$ & $8.0-12.6$ & 18 & $12.7 \pm 0.8$ & $11.0-14.4$ & 0.076 \\
\hline
\end{tabular}

$* *=\mathrm{P}<0.05$ (significant in 95\% confidence interval). (Juvenile vs. Adult)

Sexes of bats were detected by palpating (physical examination) the secondary sex organ. The age of the bats were classified as either adult or juvenile based on secondary sexual characteristics such as presence of penile barbs in case of males and elongated and white-tipped teats in the case of females. Body condition score (BCS) was classified as either fair or good, based on relative pectoral muscle mass and prominence of sternum. A fair BCS reflected a prominent sternum and minimal muscle mass where as a good BCS reflected minimally prominent sternum and substantial pectoral muscle mass.

Blood samples were collected by using $3 \mathrm{ml}$ syringe and 27-gauge needle from brachial vein. After collection, the needle was removed and $2 \mathrm{ml}$ of blood was transferred to a lithium heparin tube and transported to Physiology laboratory, Chittagong Veterinary and Animal Sciences University (CVASU) for further analysis. The samples were processed within 6 hours of collection.

\section{Blood analysis:}

Red blood cell (RBC) count, hemoglobin (Hb), hematocrits (Hct), mean corpuscular volume (MCV), mean corpuscular hemoglobin $(\mathrm{MCH})$, mean corpuscular hemoglobin concentration (MCHC), red cell distribution width (RDWs), white blood cell (WBC) count, platelets count (PLT), mean platelet volume (MPV) and platelet distribution width (PDW) were determined by automated hematology analyzer (Abacus junior vet, Diatron, Austria). However, manual techniques were used to determine the Erythrocyte sedimentation rate (ESR) described by Ghai, ${ }^{[7]}$.

\section{Statistical Analysis:}

All results were primarily entered into a computerized database (Microsoft Excel, Microsoft Corporation), stored, cleaned and transported to STATA-11. Descriptive analysis was performed to calculate Mean \pm Standard Error of Mean (SEM), 95\% Confidence Interval (CI). The value of $p$ was found significant when $p<0.05$. 


\section{RESULTS}

Ninety (90) blood samples were obtained from apparently healthy frugivorous bats after physical examination. The average body weight was found $563.5 \mathrm{~g}$ in adult bats $(n=53)$ whereas juveniles $(n=36)$ had the average body weight of $444 \mathrm{~g}$. Among all the studied bats, male bats $(\mathrm{n}=52)$ weighed $505.5 \mathrm{~g}$ whereas female bats $(\mathrm{n}=38)$ weighed 530.6g. Moreover, fair-health bats $(n=73)$ weighed $493.7 \mathrm{~g}$ and the bats with good health $(n=17)$ had the body weight of $612.1 \mathrm{~g}$.

Table 3: Hematological values based on body condition score for wild-caught large frugivorous (Pteropus giganteus) bats female (49.4 \pm 0.5$)$. However, some higher values were observed in Table-1 between male and female bats but differences were not significant.

The mean value of RBC count, Hb, HCT, RDWs, PLT and MPV of adult bats were significantly $(p<0.05)$ higher than the juvenile (Table 2). On the other hand, the average value of MCV, WBC and PDWs were higher in adult bats and the mean value of $\mathrm{MCH}, \mathrm{MCHC}$ and ESR were higher in juvenile but in both cases the differences between the age groups were not $\operatorname{significant}(p>0.05)$.

The mean value of RBC count, HCT and PLT of good health bats were significantly $(p<0.05)$ higher than the fair health (Table 3). On the other hand, the average value of $\mathrm{Hb}, \mathrm{MCHC}$, RDWs, WBC, MPV and PDWs were higher in good health bats and the

\section{Category}

Parameter Fair Good P value

\begin{tabular}{|c|c|c|c|c|c|c|c|}
\hline & $\mathrm{n}$ & Mean \pm SEM & $95 \% \mathrm{CI}$ & $\mathrm{n}$ & Mean \pm SEM & $95 \% \mathrm{CI}$ & \\
\hline RBC & 73 & $9.7 \pm 0.2$ & $9.4-10.1$ & 16 & $11.6 \pm 0.8$ & $9.8-13.4$ & $0.044^{* *}$ \\
\hline \multicolumn{8}{|l|}{$\left.\left(10^{6} / \mu \mathrm{L}\right)\right)$} \\
\hline $\mathrm{Hb} \mathrm{g} / \mathrm{dL}$ & 72 & $14.3 \pm 0.5$ & $13.4-15.3$ & 16 & $16.1 \pm 0.9$ & $14.2-18.0$ & 0.090 \\
\hline НСТ \% & 73 & $48.8 \pm 1.1$ & $46.5-51.0$ & 16 & $51.6 \pm 4.0$ & $49.2-66.1$ & $0.046^{* *}$ \\
\hline $\mathrm{MCV} \mathrm{fL}$ & 73 & $50.4 \pm 0.4$ & $49.6-51.2$ & 16 & $49.8 \pm 0.6$ & $48.4-51.1$ & 0.390 \\
\hline MCH pg & 73 & $14.9 \pm 0.2$ & $14.5-15.3$ & 16 & $14.7 \pm 0.4$ & $13.7-15.6$ & 0.666 \\
\hline $\mathrm{MCHC} \mathrm{g} / \mathrm{dL}$ & 73 & $29.4 \pm 0.4$ & $28.6-30.2$ & 16 & $29.6 \pm 0.7$ & $28.1-31.2$ & 0.772 \\
\hline RDWs fL & 73 & $34.8 \pm 0.3$ & $34.2-35.3$ & 16 & $35.5 \pm 0.5$ & $34.5-36.5$ & 0.166 \\
\hline ESR $m m$ in $1^{\text {st }}$ & 73 & $0.7 \pm 0.1$ & $0.6-0.8$ & 16 & $0.7 \pm 0.1$ & $0.4-1.0$ & 0.898 \\
\hline
\end{tabular}

$\mathrm{h}$

$\begin{array}{llllllll}\text { WBC } & 73 & 6.6 \pm 0.6 & 5.4-7.7 & 16 & 7.1 \pm 1.1 & 4.8-9.4 & 0.684\end{array}$

$\left(10^{3} / \mu \mathrm{L}\right)$

PLT $\left(10^{3} / \mu \mathrm{L}\right) \quad 22 \quad 679.1 \pm 54.4 \quad 566.1-\quad 09 \quad 920.7 \pm 60.7 \quad 780.7-1061 \quad 0.007^{* *}$

792.1

$\begin{array}{lccccccc}\text { MPV fL } & 22 & 8.3 \pm 0.3 & 7.7-8.9 & 09 & 10.0 \pm 0.4 & 8.1-9.9 & 0.178 \\ \text { PDWs fL } & 22 & 11.2 \pm 0.7 & 9.6-12.7 & 09 & 13.0 \pm 1.3 & 10.2-15.9 & 0.220\end{array}$

(

The average MCV values of male were $50.9 \pm 0.5$ which was significantly $(p<0.05)$ higher than the mean value of $\mathrm{MCV}$ and $\mathrm{MCH}$ were higher in fair health but in both cases the differences between the health statuses were not significant. 


\section{DISCUSSION}

Generally, hematological values changed with different types stress during the capture and handling of bats and other animals ${ }^{[4]}$. In present study, stress was minimized by careful handling and restraining of bats. High RBC count, $\mathrm{Hb}$ content and PCV values are higher in bats in comparison with other mammals, because bats are unique in their energy requirements and exhibit high weight-specific basal metabolic rate. Bats overcome problems of flight and high weight-specific metabolism by presenting increased blood oxygen transport properties ${ }^{[4]}$.

The average values of RBC count of present research were similar to those values represented in Miniopterus schreibersii $(10.1 \pm 0.3)$ and higher than those of Taphozous melanopogon $(8.9 \pm 0.6)$, Hipposideros lankadiva $(8.9 \pm 0.6)^{[5]}$ and captive Malaysian (Pteropus vampyrus) bats $(8.88 \pm 0.59)^{[8]}$. On the other hand, sex disparity was detected which is in agreement with the report described by Ratnasooriya et al., ${ }^{[5]}$. The values of RBC count in adults were significantly higher than the values of juvenile which was not agreement with the findings reported by Heard and Whittier ${ }^{[8]}$. This might be due to most of the adult bats in this study were found in good health state.

The HCT values of present research were similar to wild and captive Egyptian fruit bats (Rousettus aegyptiacus) $(44 \pm 2 \text { to } 58 \pm 4 \%)^{[9]}$ and higher than those reported in wild-caught Indian flying foxes ( $p$. giganteus) $(37 \pm 6 \%)^{[10]}$ and grey-headed flying foxes $(P$. poliocephalus $)(47 \pm 0.7 \%)^{[11]}$. However, $\mathrm{Hb}$ concentrations were similar to $R$. aegyptiacus $(14.4 \pm 1.4$ to $17.4 \pm 2.0 \mathrm{~g} / \mathrm{dL})$ [9] but, higher than those reported in $P$. giganteous $(13.4 \pm 2.2 \mathrm{~g} / \mathrm{dL})$ [10], and lower in P. poliocephalus $(17.9 \pm 1.3 \mathrm{~g} / \mathrm{dL})$ [11].The ESR values were correlated with the values of HCT [12] and these were similar to other mammalian species ${ }^{[15]}$.

$\mathrm{MCV}$ values were found lower in comparison with the reference values (72.11 to $91.10 \mathrm{fL}$ ) of human being ${ }^{[13]}$, which may be due to the smaller MCV favours the oxygen diffusion capacity into and out of the erythrocytes, as the smaller erythrocyte size is generally assumed to facilitate rapid diffusion. The values of $\mathrm{MCH}$ were higher than the values of cattle $(11.17 \mathrm{pg})$ and lower than the values $(24.33 \mathrm{pg})$ of human being ${ }^{[13]}$ and this might be due to lower $\mathrm{MCV}$ values. The detected MCHC values were similar to that reported in Taphozous melanopogon $(29.1 \mathrm{~g} / \mathrm{dL})$, and lower than Miniopterus schreibersii $(33.2 \mathrm{~g} / \mathrm{dL})^{[5]}$.

The mean value of RDWs was lower than human being (39-37fL) ${ }^{[14]}$. Among different groups, the values were significantly $(p<0.05)$ higher in adult. Variations were also observed in other groups such as sex and health status, but the variations were not significant.
The average values of $\mathrm{WBC}$ counts were similar to other mammalian species ${ }^{[15]}$. The WBC counts of current study were similar to $C$ castanea $(6135 \pm 848)$ but higher than that reported in Carollia sowelli $(5,573 \pm 1,543)$ and lower than Trachops cirrhosus $(7,339 \pm 1,503)$, at Neotropical bat species ${ }^{[16]}$. WBC counts were increased with increasing body weight and similar type of finding was reported by Riedesel [4]

The three important parameters such as PLT, MPV, and PDW were concerning with the platelet. The detected PLT count in the current study was higher than other mammalian species and cattle $(542000 \pm 175000)^{[17]}$. The values of MPV and PDW were within the reference values of human being [13] and the reported values were 8 to $13.15 \mathrm{fL}$ and 8.90 to $16.40 \mathrm{fL}$ respectively. The significant $(p<0.05)$ variations of PLT were observed between body condition score and age groups and this might be due to increased HCT levels.

In conclusion, this study has provided some basic hematological data for wild caught Indian flying fox (Pteropus giganteus) bats from Bangladesh to supplement existing worldwide baseline data. This is the first recorded blood related parameters of bats in Bangladesh. Further in-depth evaluation of the hematological parameters is recommended.

\section{ACKNOWLEDGEMENTS}

We are grateful to the Bat Conservation International for financial support and the Group for Conservation and Research of Bat (GCRB), One Health Young Voice Bangladesh\& Eco Health Alliance for logistic support. We are also grateful to laboratory staffs of Physiology, Biochemistry and Pharmacology of Chittagong Veterinary and Animal Sciences University, Bangladesh.

\section{REFERENCES}

1. Winter Y (1999). Flight speed and body mass of nectar-feeding bats (Glossophaginae) during foraging. J. Exper, Biol. 202(14): 1917-1930.

2. Scott JG (2000). Australian bat lyssavirus: the public health response to an emerging infection. Med. J. Australia 172 (12): 573-574.

3. Ito $\mathrm{M}$, Arai $\mathrm{YT}$, Itou $\mathrm{T}$, Sakai $\mathrm{T}$, Ito $\mathrm{FH}$, Takasaki T and Kurane I (2001). Genetic characterization and geographic distribution of rabies virus isolates in Brazil: identification of two reservoirs, dogs and vampire bats. Virology 284(2):214-222.

4. Riedesel ML (1977). Blood physiology In: Biology of Bats. Vol. iii (W. A. Wimsatt, ed.), pp 485-514, Academic Press, New York. 
5. Ratnasooriya WD, Udagama-Randeniya PV, Yapa WB, Digana PMCB and Dharmasiri MG (2005). Haematological parameters of three species of wild-caught Microchiropteran Bats, Miniopterus schreibersh, Taphozous melanopogon and Hipposideros Lankadiva in Sri Lanka. J. Sci. Univ. Kelaniya 2: 27-40.

6. McLaughlin AB, Epstein JH, Prakash V, Smith CS, Daszak P, Field HE and Cunningham AA (2007). Plasma biochemistry and hematologic values for wild-caught flying foxes (Pteropus giganteus) in India. J. Zoo. Wildl. Med. 38(3): 446-452.

7. Ghai CL (2007). A Textbook of Practical Physiology. $7^{\text {th }}$ edn. Jaypee Brothers, New Delhi, India.

8. Heard DJ and Whittier DA (1997). Hematologic and plasma biochemical reference values for three flying fox species (Pteropus sp.). J. Zoo. Wildl. Med. 28: 464-470.

9. Van Der Westhuyzen J (1988). Heamatology and iron status of the Egyptian fruit bat, Rousettus aegyptiacus. Comp. Biochem. Physiol. 90A (1): 117-120.

10. Lewis JH (1977). Comparative hematology: studies on Chiroptera, Pteropus giganteous. Comp. Biochem. Physiol. 58A: 103-107.

11. Wightman J, Roberts J, Chaffey G and Agar NS (1986). Erythrocytes biochemistry of the grey- headed fruit bat (pteropus poliocephalus). Comp. Biochem. physiol. 88B (1): 305-307.

12. Jain NC (1986). Schalm's Veterinary Hematology. Lea \& Febiger, 600 Washington Square, Philadelphia, PA 19106-4198, U.S.A.

13. Subhashree AR, Parameaswari PJ, Shanthi B, Revathy C and Parijathan BO (2012). The reference intervals for the haematological parameters in healthy adult population of Chennai, Southern India. J. Clin. Diagn. Res. Vol-6(10): 1675-1680.

14. Walters J (2002). Hematology Review: RDW Measurements and Their Meaning. ACL Lab Link, Published by ACL Laboratories: Volume $3(2), 3^{\text {rd }}$ Quarter.

15. Sharma IJ and Sigh HS (2005). Students Laboratory Manual of Veterinary Physiology. Kalyani Publishers, New Delhi-110 002, India.

16. Schinnerl M, Aydinonat D, Schwarzenberger F and Christian C (2011). Hematological survey of common Neotropical bat species from Costa Rica. J. Zoo. Wildl. Med. 42(3): 382-391.

17. Nelson JH (1974). Blood characteristics of the Holstein calf relevant in cardiopulmonary studies. J. Appl. Physiol. 37:145. 